\title{
Onomástica organometálica. 3. Geoffrey Wilkinson: o descobridor, muito para além do seu catalisador
}

\author{
Carlos C. Romão \\ Instituto de Tecnologia Química e Biológica, ITQB NOVA, Av. da república, 2780-157, Oeiras, Portugal
}

\begin{abstract}
Organometallic Onomastics. 3. Geoffrey Wilkinson: the discoverer, well beyond his catalyst As in many other aspects, the World War II was also a turning point for Inorganic Chemistry. The scientific effort of the nuclear research in this period included a man whose determination and abilities were well beyond the usual standards of academia. Geoffrey Wilkinson, a brilliant school kid from a small Yorkshire village, took his nuclear taxonomy job as a ground for the discovery and systematisation of the chemistry of a broad range of scarcely studied elements. Used to interpret previously unseen facts, he grasped the nature of the new kind of organometallic bond in ferrocene and rapidly set off to create what we now know as organometallic chemistry. Along this path, as one of the youngest professors ever appointed to the Imperial College in London, he discovered a very selective and extremely active hydrogenation catalyst that bears his name: $\mathrm{RhCl}\left(\mathrm{PPh}_{3}\right)_{\text {. }}$. This catalyst strongly motivated the development of organometallic chemistry and catalysis, but never deviated Wilkinson from his path of true fundamental research. Beyond his own Nobel Prize award for the discovery of the structure of ferrocene, his work directly opened the gates to areas where he never worked but were worthy of later Nobel prizes, as asymmetric hydrogenation and olefin metathesis.
\end{abstract}

\begin{abstract}
Tal como em vários outros aspetos, a Segunda Guerra Mundial também foi um ponto de viragem para a Química Inorgânica. O esforço científico posto na investigação nuclear nesse período incluiu um homem cuja determinação e capacidades estavam muito acima dos padrões académicos normais. Geoffrey Wilkinson, um aluno brilhante da escola duma pequena aldeia do Yorkshire, fez deste trabalho de taxonomia nuclear um campo para a descoberta e sistematização da química duma grande variedade de elementos muito pouco estudados. Habituado a interpretar factos nunca antes observados, rapidamente percebeu a natureza do novo tipo de ligação química do ferroceno e rapidamente iniciou a criação daquilo que hoje conhecemos como química organometálica. Nesta caminhada, como um dos mais jovens professores alguma vez nomeados para o Imperial College de Londres, descobriu um catalisador de hidrogenação altamente ativo e seletivo que tem o seu nome: $\mathrm{RhCl}\left(\mathrm{PPh}_{3}\right)_{3}$. Este catalisador foi um grande motivador do desenvolvimento da química organometálica e da catálise, mas nunca desviou Wilkinson do seu percurso de investigação fundamental. Para além do seu prémio Nobel pela descoberta da estrutura do ferroceno, o seu trabalho abriu diretamente os portões para áreas nas quais nunca trabalhou mas que mais tarde valeram prémios Nobel, como a hidrogenação assimétrica e a metátese de olefinas.
\end{abstract}

Quando em 1965 comunicou a atividade catalítica do complexo RuCl($\left(\mathrm{PPh}_{3}\right)_{3}$ na hidrogenação de alcenos em solução homogénea à pressão atmosférica, Geoffrey Wilkinson já era um dos expoentes máximos da Química Organometálica e Inorgânica [1]. De acordo com a Web of Science esta comunicação já era o seu $194^{\circ}$ artigo! De facto, olhando a sua carreira científica desde o início, é quase inevitável concluir que Wilkinson foi um dos maiores responsáveis pelo renascimento da Química Inorgânica e pelo crescimento explosivo da Química Organometálica. Iniciado durante a Segunda Guerra Mundial, o seu percurso científico desenrolou-se de forma estonteante, pela rapidez e pela novidade, de modo a tornar-se aos 34 anos (1955) num dos mais jovens professores de sempre no Imperial College de Londres.

Geoffrey Wilkinson (Figura 1) nasceu em Springside, uma pequena cidade do Yorkshire cuja vida era dominada pela mineração de carvão e por uma fiação de algodão onde trabalhava a sua mãe.

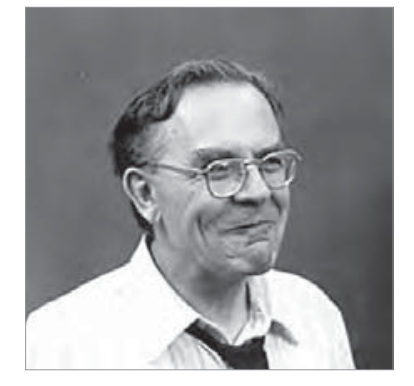

Figura 1 - Geoffrey Wilkinson (1921-1996)
Seu pai era pintor de construção civil mas um dos seus tios maternos tinha uma fábrica de sal de Epsom (sulfato de magnésio) e sal de Glauber (sulfato de sódio) que abastecia a indústria farmacêutica. Já agora dê uma volta pela internet e veja as maravilhas medicinais que estes dois sais são supostos fazer. E se já se interrogou sobre a diferença de intensidade de sabor que existe entre o sal-gema e o sal marinho, fique a saber que é devida à presença neste último de $\mathrm{MgSO}_{4}$, conhecido em alemão por Bittersalz (sal amargo). E já que estamos num contexto de onomástica organometálica, demos uma mãozinha à onomástica inorgânica que atribuiu o nome de sal de Glauber ao químico Johann Rudolph Glauber que o descobriu e sintetizou em 1625 (!) e lhe deu o nome de "sal mirabilis" provavelmente devido às suas potentes propriedades laxativas.

Foi no meio destes sais que Wilkinson teve o seu primeiro contacto com a química inorgânica e aprendeu a brincar no laboratório. Com a bolsa que ganhou no fim do ensino primário foi estudar para Todmarten, uma localidade próxima cuja escola secundária veio a ficar famosa por ser provavelmente a única no mundo que educou dois prémios Nobel: J. Cockcroft, (Física, 1951) e G. Wilkinson (Química, 1973). 
Licenciou-se (1939) e doutorou-se (1941) no Imperial College de Londres. A sua capacidade científica colocou-o num grupo de jovens selecionados para participar no projeto de energia atómica conjunto dos Estados Unidos, Reino Unido e Canadá, a decorrer em Montreal e Chalk River. Nesse projeto a sua atividade centrou-se na identificação e determinação do rendimento dos elementos gerados por reações de fissão de isótopos de urânio. Em 1946 foi trabalhar para a Universidade de Berkeley com Glen Seaborg, onde a sua atividade de "taxonomia nuclear" aprofundou a sua familiaridade com a química e as propriedades de tudo quanto era metal pesado e radioisótopo (produziu e caracterizou 89 isótopos, o que parece ser ainda um record mundial) construindo assim um saber enciclopédico que marcou a sua carreira científica. Desaconselhado que foi de tentar uma carreira na área da radioquímica no Reino Unido, ingressou no MIT (1950) onde se dedicou ao estudo da química de coordenação de ligandos de carbono (CO, alcenos, alcinos), ou seja, à química organometálica. No ano seguinte, Harvard convidou-o para professor de química nuclear. No entanto, a química organometálica já dominava os seus interesses quando o artigo de Kealy and Pauson apareceu na revista Nature em 1952. Nesse artigo, os autores descreviam um novo composto de ferro obtido de acordo com o esquema 1 [2].

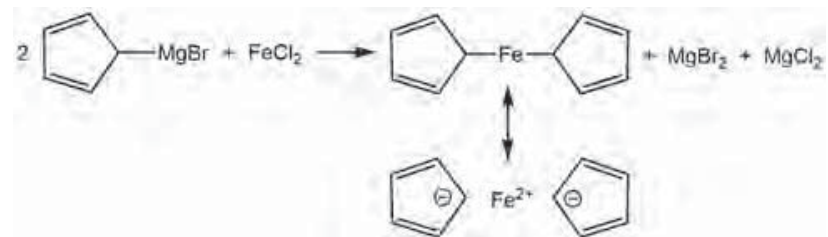

Esquema 1 - Síntese e ligação química do bis-ciclopentadienilo de Fe proposta por Kealy e Pauson [2].

Com a sua enorme experiência na química dos metais de transição Wilkinson percebeu que essa não poderia ser a estrutura ficando famosa a exclamação que ele fez para si próprio “Jesus Christ, it can't be that!”. Juntamente com Robert Woodward (sim, o das regras...) e colaboradores foi proposta uma estrutura completamente revolucionária, com base em medidas de momentos dipolares e magnéticos e espetros de infravermelho: a estrutura da Figura 2, posteriormente chamada "estrutura sandwich" [3].

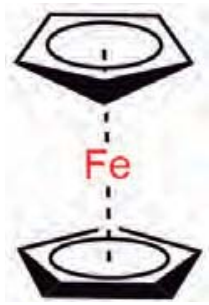

Figura 2 - Estrutura do ferroceno.

Em Munique, Ernst O. Fischer não só confirmou esta estrutura sanduíche por cristalografia de raios-X como estendeu o conceito produzindo impensáveis e altamente reativas sanduíches como o bis-benzeno crómio ou o cobaltoceno. A importância destas descobertas veio a ser a causa próxima da atribuição do Prémio Nobel da Química a Wilkinson e Fischer em 1973. Como se poderá calcular, nem todos ficaram contentes com esta distinção e a história de algumas dessas controvérsias, como descrita por Helmut Werner, é muito instrutiva da natureza humana e do pensamento do Comité Nobel [4]. Sentindo-se injustiçado, Woodward queixou-se ao Comité Nobel reclamando para si o essencial da proposta do nome ferroceno, por analogia com outros compostos aromáticos, e da sua estrutura. De facto, o que mais cativou a atenção de Woodward no ferroceno foi a aromaticidade dos anéis que provou através da sua fácil acilação por uma reação de Friedel-Crafts. A partir daí Woodward deixou de ligar ao ferroceno e dedicou-se a outras descobertas da química orgânica. Pelo contrário, percebendo as potencialidades e o interesse de explorar este novo tipo de ligação metal-carbono, Wilkinson lançou-se furiosamente ao trabalho de desenrolar o fio duma nova meada chamada Química Organometálica. Assim, entre a submissão da estrutura do ferroceno em março de 1952 e o final de 1954 publicou 18 artigos nos quais sintetizou e caracterizou complexos de ciclopentadieno de metais de todos os grupos da série de transição e ainda de escândio, ítrio e alguns lantanídeos. É importante dizer que os papéis do ligando ciclopentadienilo e o de alguns dos metalocenos foram fundamentais em muitos dos avanços que a química organometálica produziu nas décadas seguintes. Basta lembrar a revolução da polimerização catalítica de alcenos operada com base nos zirconocenos, cujo primeiro exemplar $\left(\mathrm{Cp}_{2} \mathrm{ZrCl}_{2}\right)$ ele produziu em 1954. Apesar deste extraordinário abrir de portas a uma química inteiramente nova e de imperscrutável potencial, Harvard não lhe deu “tenure” (posição permanente). Assim, após 4 anos, voltou a Inglaterra onde lhe foi oferecida a única cátedra de Química Inorgânica existente no reino. Wilkinson manteve-se neste posto, no Imperial College de Londres, todo o resto da sua vida científica. Tornou-se professor emérito em 1988 mas continuou a sua investigação até à semana da sua morte (26 de setembro de1996) num laboratório que lhe foi posto à disposição pela firma Johnson Matthey.

No seu novo posto retomou o trabalho com a habitual intensidade. Nas palavras de Malcolm L. H. Green um dos seus primeiros doutorandos em Londres, "O espírito do seu grupo de investigação era mais o de uma urgente corrida ao ouro no Oeste do que o estudioso, disciplinado e calmo espírito expectável na academia. Cometiam-se muitos erros, havia explosões e os incêndios lavravam” [5].

O trabalho começou com a síntese de complexos organometálicos combinando metais com ligandos ciclopentadienilo $\left(\mathrm{Cp}=\mathrm{C}_{5} \mathrm{H}_{5}\right)$, alquilos, arilos e hidreto com CO. Destas reações surgiram novos compostos cuja química se expandiu em horizontes nunca dantes imaginados. Não admira, portanto, que o seu artigo mais citado não seja o da estrutura do $\mathrm{Cp}_{2} \mathrm{Fe}$ (3. ${ }^{\circ}$ mais citado, com 620 citações) mas sim um dos seus primeiros trabalhos no Imperial College que contém compostos como os representados na Figura 3 (1023 citações) [6].

A sua veia de químico de síntese está bem expressa na sua lista de publicações onde 6 das primeiras 10 mais citadas (todas com mais de 450 citações) descrevem os complexos que foram a base do desenvolvimento experimental da química organometálica, i.e. os seus mais versáteis materiais de partida. As restantes três são dedicadas à catálise homogénea em reações de hidroformilação e de hidroge- 

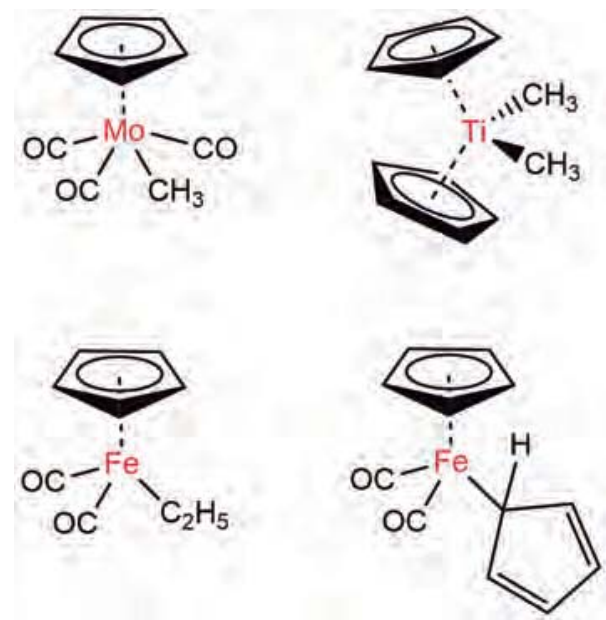

Figura 3 - Alguns compostos organometálicos-chave no desenvolvimento da química organometálica.

nação de alcenos com complexos de ródio e ruténio. Chegámos, portanto, ao território do composto que dá o título deste artigo: o catalisador de Wilkinson (1) preparado de acordo com a eq. 1 e representado na figura 4.

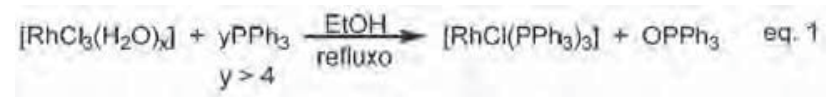

Wilkinson descobriu o complexo 1 em 1965 quase em simultâneo com R. Coffey, um químico da ICI (Imperial Chemical Industries) [1]. No entanto, com a sua habitual intensidade, Wilkinson rapidamente explorou a reatividade deste complexo tornando-o num marco da catálise homogénea [7].

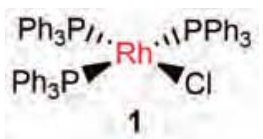

Figura 4 - Estrutura do catalisador de Wilkinson.

Como é vulgar em ciência, a importância do "fator inesperado" (serendipity, em inglês), fica demonstrada pelo facto de a reação da eq. 1 apenas funcionar com trifenilfosfina $\left(\mathrm{PPh}_{3}\right)$ e mais nenhuma outra fosfina. Complexos análogos podem ser feitos por reação de $[\mathrm{Ru}(\mu-\mathrm{Cl})(\mathrm{COD})]_{2}$ com a fosfina $\left(\mathrm{PR}_{3}\right)$ pretendida. Por outro lado, fica demonstrada a (muitas vezes esquecida) importância de se fazer uma caracterização completa dos compostos. Assim, quando se julgava que a estrutura quadrangular plana de $\mathbf{1}$ com os seus 16 eletrões de valência típicos dos complexos com configuração eletrónica $\mathrm{d}^{8}$ fosse perfeitamente estável, a determinação do peso molecular deu um valor anormalmente baixo indicando que $\mathbf{1}$ se dissociava extensivamente em solução de benzeno, de acordo com a eq. 2 .

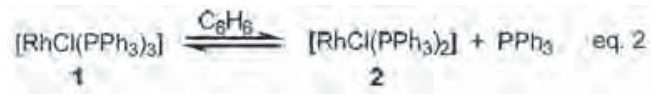

Espécies com 14 eletrões de valência, como 2, são raras e altamente reativas e provavelmente estabilizadas pelo solvente como em $\left[\mathrm{RhCl}\left(\mathrm{PPh}_{3}\right)_{2}(\mathrm{~S})\right](2 \cdot \mathrm{S})$ (S = solvente). De facto, a reação de $\mathbf{1}$ com CO é instantânea e produz o complexo [RhCl(CO) $\left.\left(\mathrm{PPh}_{3}\right)_{2}\right]$ análogo do complexo de Vaska cuja química já discutimos em anterior artigo desta série [8]. Ao contrário de $\mathbf{1},\left[\mathrm{RhCl}(\mathrm{CO})\left(\mathrm{PPh}_{3}\right)_{2}\right]$ não perde o CO nem por reação com $\mathrm{PPh}_{3}$ pura, fundida a $100^{\circ} \mathrm{C}$ ! A afinidade de 2 por $\mathrm{CO}$ é tal que reage com aldeídos e com outros reagentes análogos $\mathrm{RC}(=\mathrm{O}) \mathrm{X}(\mathrm{X}=\mathrm{Cl}, \mathrm{Br}, \mathrm{CN}$, CO-R', $\mathrm{CH}_{2} \mathrm{COOCH}_{3}$ ) para dar $\left[\mathrm{RhCl}(\mathrm{CO})\left(\mathrm{PPh}_{3}\right)_{2}\right]$ e $\mathrm{RH}$ ou RX (eq. 3). Esta reação é atualmente conhecida por descarbonilação de Tsuji-Wilkinson e foi reportada por Tsuji logo após a primeira publicação da síntese de $\mathbf{1}$ [9].

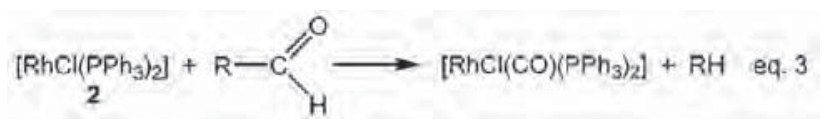

Soluções de 1 em benzeno ou clorofórmio absorvem etileno $\left(\mathrm{CH}_{2}=\mathrm{CH}_{2}\right)$ para dar $\mathrm{RhCl}\left(\mathrm{PPh}_{3}\right)_{2}\left(\eta^{2}-\mathrm{C}_{2} \mathrm{H}_{4}\right)$ (3). Esta reação é reversível e basta borbulhar $\mathrm{N}_{2}$ na solução de $\mathbf{3}$ para retirar parte do etileno. Outros alcenos, como o propeno, o estireno, etc. também se ligam a 2 mas com constantes de estabilidade cerca de mil vezes menores. A reação de 1 com $\mathrm{H}_{2}$ dá $\left[\mathrm{RhClH}_{2}\left(\mathrm{PPh}_{3}\right)_{3}\right]$ (4) e é reversível, bastando borbulhar $\mathrm{N}_{2}$ para retirar o hidrogénio. No entanto, a reação de $\mathbf{2} \cdot \mathbf{S}$ com $\mathrm{H}_{2}$ é muito mais rápida e o ciclo descrito pela eq. 4 pode ser repetido indefinidamente.

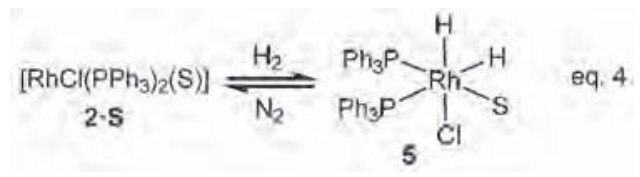

À data em que foi feita, a eq. 4 só encontrava paralelo na adição de $\mathrm{H}_{2}$ ao complexo de Vaska [10]. Este paralelo estende-se a outras reações de adição oxidativa de $\mathbf{2}$ (ou 1) com substratos como $\mathrm{CH}_{3} \mathrm{I}, \mathrm{HCl}, \mathrm{Cl}_{2}, \mathrm{O}_{2}$ e outros. Contudo, a química do di-hidreto 5 revelou-se muito mais ativa do que a do análogo $\mathrm{IrClH}_{2}(\mathrm{CO})\left(\mathrm{PPh}_{3}\right)_{2}$. No seu longo artigo de 1966 [7], Wilkinson dedica uma parte A à síntese e propriedades do complexo 1 e uma parte $B$ à hidrogenação catalítica de olefinas e acetilenos. Esta apresenta, de chofre, a fabulosa atividade catalítica deste complexo. Aqui vão os destaques: o complexo 1 é extremamente eficiente na hidrogenação de alcenos não conjugados e de acetilenos à temperatura ambiente e a pressões $\leq 1$ atm. A Figura 5 apresenta tanto a ordem decrescente de reatividade dos alcenos como os grupos funcionais que não são hidrogenados nestas condições reacionais. Como se vê, a quimiosseletividade desta hidrogenação é excelente.

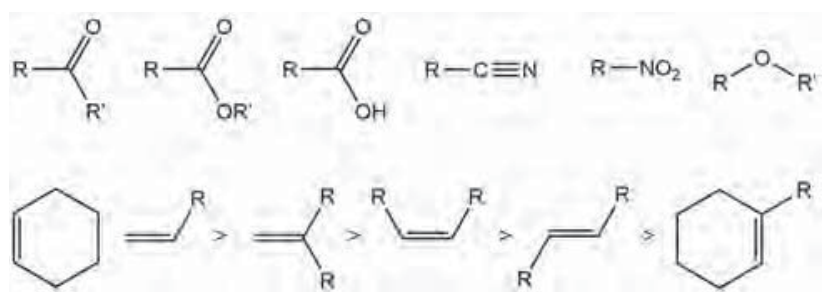

Figura 5 - Em cima: funções não hidrogenadas por 1. Em baixo: ordem decrescente de reatividade de alcenos.

A falta de reatividade dos grupos carbonilo mostra que as ligações Rh-H não são iónicas. 
Os alcenos internos são reduzidos mais devagar do que os terminais, os cis-dissubstituídos são reduzidos mais depressa do que os trans, e os conjugados (p. ex. butadieno) não são reduzidos nestas condições, pois necessitam de altas pressões (ca. 60 atm). Os alcenos quelantes não conjugados (p. ex. cicloocta-1,5-dieno) são reduzidos lentamente a $1 \mathrm{~atm}$, mas rapidamente a pressões mais altas. Por fim, um dado surpreendente: ao contrário dos outros alcenos terminais, o etileno, $\mathrm{C}_{2} \mathrm{H}_{4}$, não é hidrogenado embora reaja com o complexo $\mathrm{RhClH}_{2}\left(\mathrm{PPh}_{3}\right)_{3}$ à temperatura ambiente. Isto quer dizer que o etileno inibe a adição de $\mathrm{H}_{2}$ ao centro metálico de 2 . Como o etileno é um ácido $\pi$ quase tão forte como o $\mathrm{CO}$, a adição oxidativa de $\mathrm{H}_{2}$ ao complexo $\mathrm{RhCl}\left(\mathrm{PPh}_{3}\right)_{2}\left(\eta^{2}-\mathrm{C}_{2} \mathrm{H}_{4}\right)$ não ocorre, tal como também não ocorre no complexo $\operatorname{RhCl}(\mathrm{CO})\left(\mathrm{PPh}_{3}\right)_{2}$. Os alcenos substituídos coordenam-se muito mais fracamente ao complexo 2, pelo que não inibem a hidrogenação. A atividade das hidrogenações normais é tão elevada que uma solução de $1\left(10^{-3} \mathrm{M}\right)$ em benzeno, com $\mathrm{H}_{2}$ a $1 \mathrm{~atm}$, hidrogena alcenos terminais com tal velocidade que a solução entra rapidamente em refluxo $\left(80^{\circ} \mathrm{C}\right)$. Neste mesmo artigo são apresentados estudos cinéticos e os primeiros estudos relativos à estereoquímica da reação. Neste último caso, ficou estabelecido que a hidrogenação dum alceno terminal $\mathrm{RCH}=\mathrm{CH}_{2}$ com uma mistura de $\mathrm{H}_{2}$ e $\mathrm{D}_{2}$ dá $\mathrm{RCH}_{2}$ $-\mathrm{CH}_{3}$ e RCHD-CH $\mathrm{D}_{2} \mathrm{D}$, mas apenas dá quantidades muito reduzidas (ca. 5\%) de produtos de troca H/D como seriam, p. ex., $\mathrm{RCH}_{2}-\mathrm{CH}_{2} \mathrm{D}$ (Esquema 2). Também se demonstra que a estereoquímica da adição de $\mathrm{H}_{2}$ ou $\mathrm{D}_{2}$ a uma ligação $\mathrm{C}=\mathrm{C}$ é cis, i.e., ambos os átomos de $\mathrm{D}_{2}$ ou $\mathrm{H}_{2}$ são adicionados do mesmo lado da ligação $\mathrm{C}=\mathrm{C}$ (Esquema 2).

Os estudos cinéticos mostram que este catalisador ultrapassa em eficiência, e especialmente em seletividade, os métodos tradicionais de hidrogenação catalítica heterogénea como por ex. a hidrogenação com Raney níquel.

O esquema 3 condensa toda a química de 1 que é relevante para a sua atividade de hidrogenação. Todas as espécies aqui representadas foram caracterizadas por métodos espetroscópicos exceto as que se encontram dentro do retângulo, que são precisamente as que se pensa constituírem o mecanismo catalítico propriamente dito. Esta situação não é de todo única nem sequer inesperada. De facto, as espécies ativas em processos catalíticos só muito raramen-

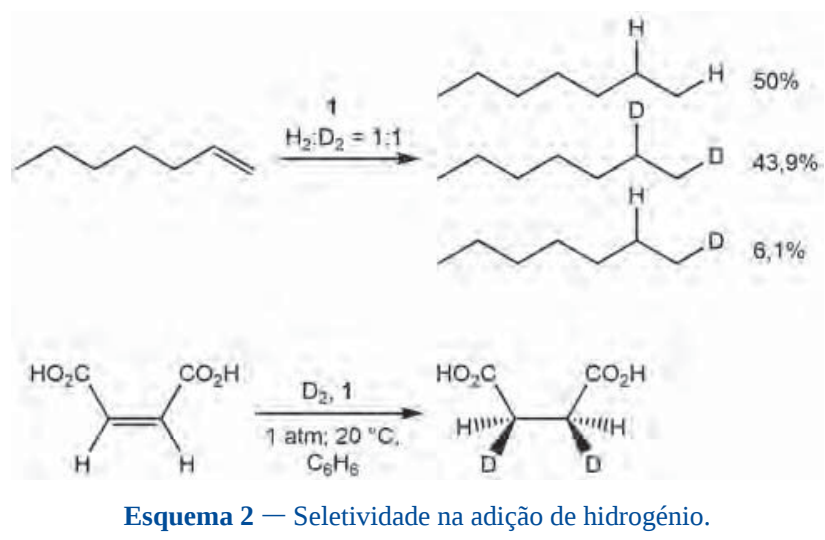

te são observadas, pois a sua reatividade é tão alta que a sua concentração em solução é sempre ínfima e transiente, impossibilitando a sua observação direta. A altíssima atividade catalítica do catalisador de Wilkinson coloca as suas espécies ativas exatamente dentro do quadro destas limitações. No entanto, o conhecimento do modus operandi da química organometálica e das suas reações elementares permite escrever este mecanismo com bastante segurança. Como se indica, as espécies dentro do retângulo catalítico alternam entre os 16 e os 18 eletrões, de acordo com a regra de Tolman, também já apresentada no caso da hidroformilação catalítica proposta por Heck [11 e referências aí citadas].

Em solução, 1 dissocia-se rapidamente para dar a espécie insaturada (14-e) $\mathrm{RuCl}\left(\mathrm{PPh}_{3}\right)_{2}$ (2) que é estabilizada pelo solvente como $\mathbf{2} \cdot \mathbf{S}$ e se hidrogena, por adição oxidativa de $\mathrm{H}_{2}$, para dar $\mathbf{5}$. Alternativamente, a sequência $\mathbf{1} \rightarrow \mathbf{4}$ $\rightarrow 5$ também conduz ao ciclo catalítico. No entanto, como 2/2.S reage com $\mathrm{H}_{2} 10^{4}$ vezes mais rápido do que $\mathbf{1}$, a via $\mathbf{1} \rightarrow \mathbf{2 \cdot S} \rightarrow \mathbf{5}$ é a principal entrada no ciclo catalítico. A coordenação do alceno a 5 gera o intermediário $\mathbf{6}$ ativando-o para a reação de inserção migratória que leva a 7. Esta transformação é o passo controlador da velocidade da reação (rate determining step). A fácil eliminação redutiva do alcano a partir do alquil-hidreto 7 liberta o produto da reação e regenera o catalisador $\mathbf{2} / \mathbf{2} \cdot \mathbf{S}$. Usando ciclo-hexeno como substrato, Halpern, um dos pioneiros da cinética em química inorgânica e organometálica, estabeleceu este mecanismo [12 e referências aí citadas].

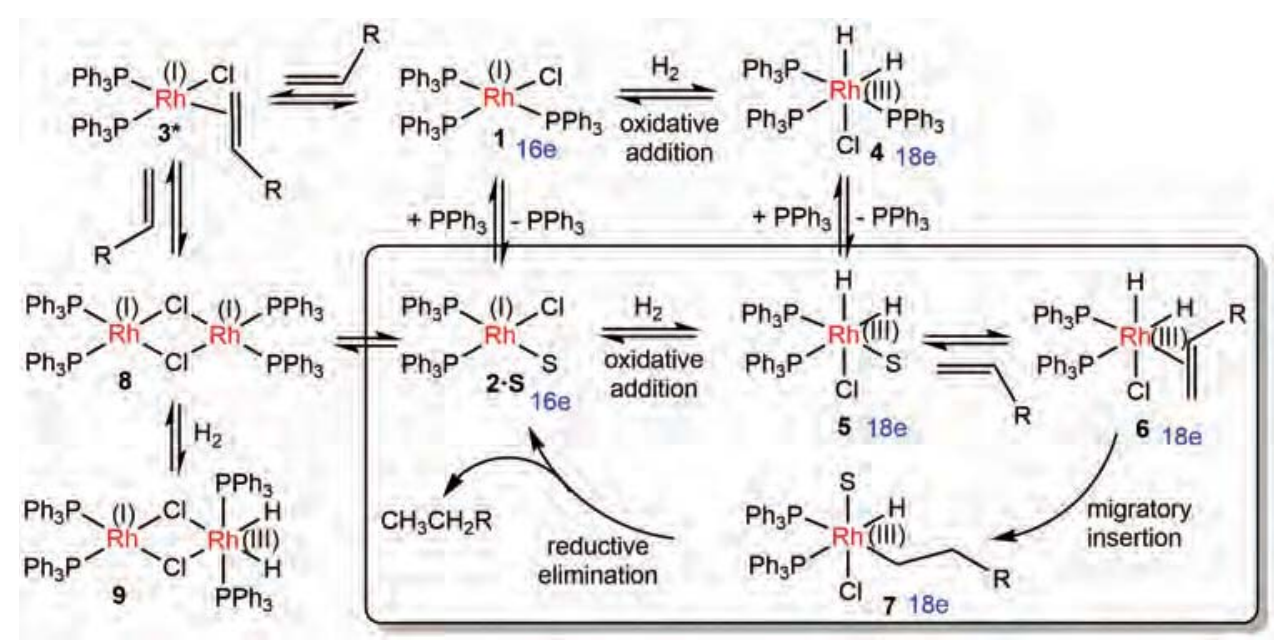

Esquema 3 - Mecanismo da hidrogenação catalítica com o catalisador de Wilkinson 1. 
As espécies $3^{*}, 8$ e 9, foram todas observadas e caracterizadas nas reações catalíticas, mas são inibidoras das mesmas reduzindo a sua velocidade. O caso do complexo 3 com etileno é um exemplo de inibição pois, como se disse atrás, o etileno não é hidrogenado por este catalisador. Espécies como 9 podem ter alguma atividade de hidrogenação mas é mais fraca do que a de 2 .

A natureza dos substituintes nas fosfinas afeta a reatividade do catalisador, de acordo com a ordem de reatividades relativas (entre parêntesis) para análogos de $\mathbf{1}$ com as várias fosfinas substituídas: $\mathrm{P}\left(4-\mathrm{ClC}_{6} \mathrm{H}_{4}\right)_{3}(1.8)<\mathrm{P}\left(\mathrm{C}_{6} \mathrm{H}_{5}\right)_{3}$ (41) $<\mathrm{P}\left(4-\mathrm{MeC}_{6} \mathrm{H}_{4}\right)_{3}(86)<\mathrm{P}\left(4-\mathrm{MeOC}_{6} \mathrm{H}_{4}\right)_{3}(100)$.

Aumentando o poder doador da fosfina facilita-se a adição oxidativa do $\mathrm{H}_{2}$ acelerando-se a reação. No entanto, fosfinas fortemente doadoras como $\mathrm{PEt}_{3}$ ou PPhEt ${ }_{2}$ estabilizam as espécies de Rh(III) de tal forma que inibem a atividade catalítica.

Além da hidrogenação e da descarbonilação, 1 também catalisa hidrossililações (adição de $\mathrm{H}-\mathrm{SiR}_{3}$ a uma ligação $\mathrm{C}=\mathrm{C}$ ou $\mathrm{C} \equiv \mathrm{C}$ ). A importância que hoje se dá à chamada química verde sugere a possibilidade de usar água como solvente das hidrogenações. Com essa finalidade, foi preparado o complexo RhCl(TPPMS) (10) $_{3}$ [TPPMS = $\left.\mathrm{PPh}_{2}\left(\mathrm{C}_{6} \mathrm{H}_{4} \mathrm{SO}_{3} \mathrm{Na}\right)\right]$ um análogo do catalisador de Wilkinson solúvel em água. De facto, 10 reage com $\mathrm{H}_{2}$ em solução aquosa mas a reação não forma $\mathrm{RhClH}_{2}$ (TPPMS) 3 mas sim RhH(TPPMS) (eq 5). A hidrogenação é possível mas o mecanismo é completamente distinto, tal como a atividade e a seletividade [13]. Este caso exemplifica a grande diferença que a água tem relativamente aos solventes orgânicos e a forma como pode modificar a química dos seus solutos.

\section{$\left[\mathrm{RhCl}(\mathrm{TPPMS})_{3}\right]+\mathrm{H}_{2} \longrightarrow\left[\mathrm{RhH}(\mathrm{TPPMS})_{3}\right]+\mathrm{Cr}+\mathrm{H}^{+}$eq. 5}

A elevadíssima atividade e seletividade do catalisador de Wilkinson abriu caminho à pesquisa de novos catalisadores de hidrogenação em fase homogénea. Os resultados mais notáveis desta busca são os catalisadores de Schrock-Osborne e de Crabtree representados na Figura 6, e que apresentam atividades catalíticas 6-10 vezes superiores à do catalisador de Wilkinson.

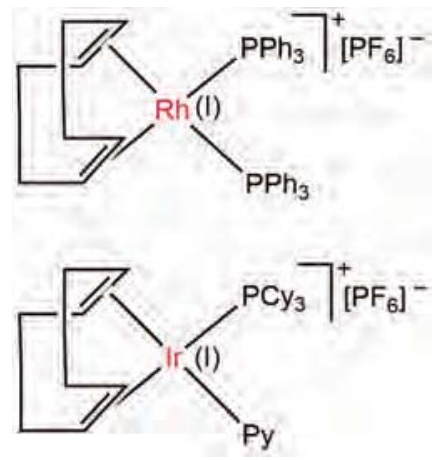

Figura 6 - Em cima: catalisador de Schrock-Osborne. Em baixo: catalisador de Crabtree. A diolefina é o cicloocta-1,5-dieno (COD), Cy = ciclo-hexilo e Py = piridina.

Neste ponto sabe bem relatar a notável contribuição portuguesa para esta corrida. Ivan Villax, fundador da Hovione, estava interessado na utilização dum catalisador de hidrogenação que substituísse o catalisador de Wilkinson num dos passos da síntese do antibiótico doxiciclina patenteada por farmacêuticas americanas. Na sua pesquisa, fez reagir 1 com hidrazina $\left(\mathrm{H}_{2} \mathrm{NNH}_{2}\right)$ e obteve um composto com melhor atividade catalítica. Esta molécula catiónica foi caracterizada estruturalmente por difração de raios-X como um dímero dicatiónico com dois contra-iões $\mathrm{Cl}^{-}(\mathbf{1 1})$. Apesar da clara diferença entre $\mathbf{1 1}$ e 1, a tremenda batalha de propriedade industrial em torno da síntese da doxiciclina, que envolveu pareceres de muitas das grandes sumidades da química organometálica e da catálise nos anos 80, apenas foi vencida quando, por substituição de $\mathrm{Cl}^{-}$por $\mathrm{NO}_{3}{ }^{-}$, se obteve um catalisador 10 vezes mais ativo e, também ele caracterizado por difração de raios-X. Este novo catalisador 12 possui um grupo $\mathrm{CH}_{2}$, certamente derivado do solvente $\mathrm{CH}_{3} \mathrm{OH}$, que liga as duas hidrazinas. Seguramente, não tendo nada que ver com o catalisador de Wilkinson, não infringia as patentes anteriores. Este resultado foi crucial para o progresso e prestigio da Hovione que não só aumentou a sua própria produção de doxiciclina como acelerou a sua trajetória ascendente no mundo da síntese de ativos farmacêuticos.
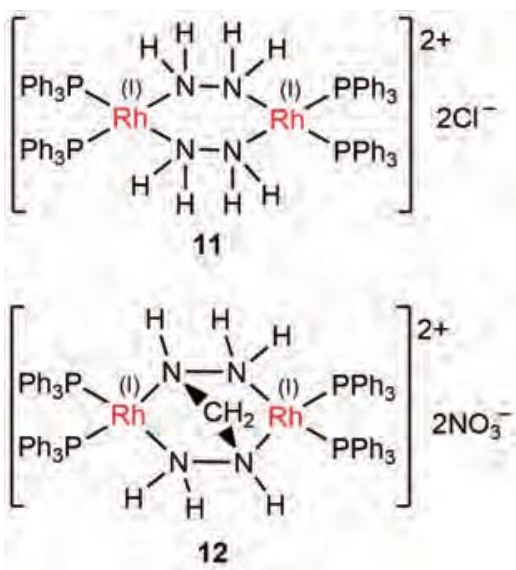

Figura 7 - Catalisadores do processo Hovione da síntese de doxiciclina.

Uma das questões centrais da hidrogenação de alcenos, particularmente quando se trabalha no domínio dos produtos naturais e farmacêuticos, é a possibilidade de controlar a estereoquímica da adição de $\mathrm{H}_{2}$ a um alceno proquiral a fim de favorecer a formação de um determinado enantiómero. Este processo, chamado de hidrogenação assimétrica, começou em 1968 usando 1 como catalisador na presença duma fosfina quiral. Os resultados foram muito fracos mas não foram negativos: o excesso enantiomérico (ee) foi pequeno mas positivo como se mostra na Figura 8.

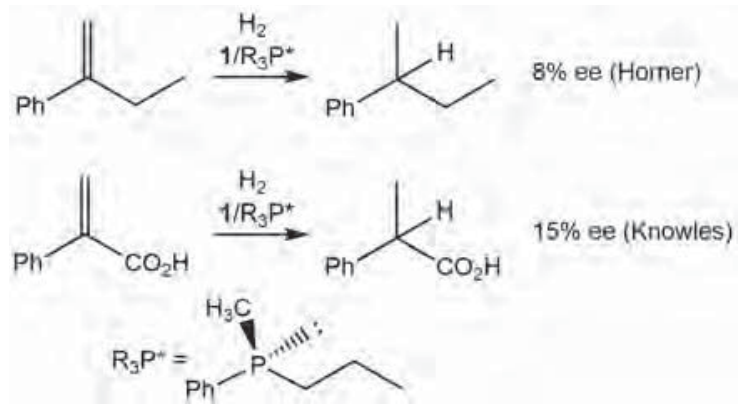

Figura 8 - Primeiros ensaios de hidrogenação assimétrica de alcenos. 
Estes resultados primitivos foram definitivamente ultrapassados quando Kagan, em 1972, percebeu que substituindo as duas fosfinas do $\mathrm{RhCl}\left(\mathrm{PPh}_{3}\right)_{2}$ (2) por uma fosfina bidentada quiral tornava a espécie ativa quiral e muito mais estável devido ao efeito quelante. Deste modo, usando DIOP como ligando quiral, conseguiu a primeira hidrogenação catalítica com elevados valores de excesso enantiomérico [14]. Na Figura 9 apresenta-se a estrutura da DIOP e da DIPAMP duas das fosfinas quirais mais antigas.
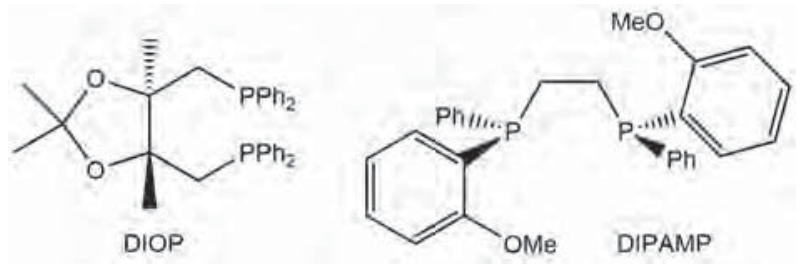

Figura 9 - Estruturas da DIOP e da DIPAMP.

Esta abordagem estabeleceu-se de forma meteórica e com resultados espantosos. A eq. 6 mostra a síntese da fenilalanina com 93\%ee publicada por Knowles em 1975 usando o catalisador de Schrock-Osborn modificado com DIPAMP [15].

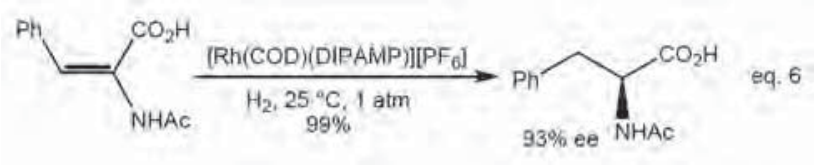

O número de fosfinas quirais tornou-se enorme e os resultados obtidos acabaram por gerar o Prémio Nobel de 2001 que distinguiu Knowles e Noyori pelos seus avanços na hidrogenação assimétrica e Sharpless pela epoxidação assimétrica.

Por seu lado, depois de abrir esta autêntica comporta, Wilkinson deixou a hidrogenação, e foi ver o que o seu favorito ródio faria na hidroformilação. Aqui o trabalho mais avançado era o de Heck, com o catalisador $\mathrm{CoH}(\mathrm{CO})_{4}$ [11], pelo que a comparação com o Rh, que é isoeletrónico, fazia todo o sentido. O resultado foi a descoberta do catalisador $\mathrm{RhH}(\mathrm{CO})\left(\mathrm{PPh}_{3}\right)_{3}$ que opera em condições de pressão e temperatura muito suaves e usado no processo industrial de produção de butanal da Union Carbide.

De acordo com o Comité Nobel, Wilkinson foi premiado por causa da descoberta do ferroceno. Contudo, é evidente que esta abertura de novos horizontes à catálise também foi decisiva para essa nomeação. No entanto, a catálise per se não era a verdadeira paixão química de Wilkinson. A sua postura era mais a do explorador para quem o importante era abrir as fronteiras do conhecimento. Fê-lo trabalhando com mais de metade de todos os elementos da Tabela Periódica, incluindo praticamente todos os metais de transição bem como muitos lantanídeos, actinídeos e elementos representativos. Todavia, a sua praia favorita foi a dos chamados “platinum metals” (Ru, Os, Rh, Ir, Pd e Pt) e em particular os três $\mathrm{R}: \mathrm{Re}, \mathrm{Ru}, \mathrm{Rh}$. Com estes elementos publicou mais de $1 / 3$ dos seus 557 artigos. Os sais destes elementos eram-lhe oferecidos pela companhia JohnsonMatthey para onde ele devolvia, para reciclagem, os respetivos resíduos produzidos no seu laboratório.
Em todo o seu trabalho uma das questões que mais o fascinou foi a compreensão da ligação $\sigma$ metal-carbono, na sua estabilidade e reatividade. Foi, aliás, sobre esse tema a sua lição Nobel: The long search for stable transition metal alkyls [16]. De facto, o número de compostos com ligações $\sigma \mathrm{M}-\mathrm{C}$ era muito limitado sem que fosse inteiramente claro porquê. Ainda em 1968 se aceitava quase como dogma que assim tinha de ser. A ligação $\sigma \mathrm{M}-\mathrm{C}$ era fraquinha $\mathrm{e}$ portanto fugidia! [17].

Como já se disse mais acima, o uso de combinações de ligandos $\mathrm{Cp}$, fosfinas e CO grandemente impulsionado pelos trabalhos de Wilkinson, produziu uma série de novos compostos que suportavam ligações $\sigma \mathrm{M}-\mathrm{C}$ perfeitamente estáveis. O estudo de muitos destes complexos, que até teve grande expressão na escola portuguesa de termoquímica, mostrou que estas ligações não eram anormalmente fracas, mas absolutamente normais. Sem mais, argumentava-se que assim eram devido à presença doutros ligandos ditos “estabilizadores”. Wilkinson nunca comprou essa ideia e sempre defendeu que a instabilidade das ligações $\sigma \mathrm{M}-\mathrm{C}$ era de natureza cinética e dependia fortemente da insaturação coordenativa do metal. Isso era fácil de aceitar quando os alquilos tinham hidrogénios $\beta$ que originavam a decomposição via eliminação $\beta$ com formação duma ligação M-H e libertação dum alceno. No entanto, como explicar que o $\mathrm{Ti}\left(\mathrm{CH}_{3}\right)_{4}$ se decompõe a $-70^{\circ} \mathrm{C}$ se não tem hidrogénios $\beta$ ? A hipótese da insaturação coordenativa ganha força pois se adicionarmos bipiridina o complexo octaédrico Ti( $\left.\mathrm{CH}_{3}\right)_{4}$ (bipy) torna-se muito mais estável. Wilkinson, fazendo uso da sua habitual persistência e combatividade, encetou então uma busca sistemática de síntese de compostos com ligações $\sigma \mathrm{M}-\mathrm{C}$ com alquilos incapazes de suportar a eliminação $\beta$, alguns dos quais exemplificados na Figura 10.

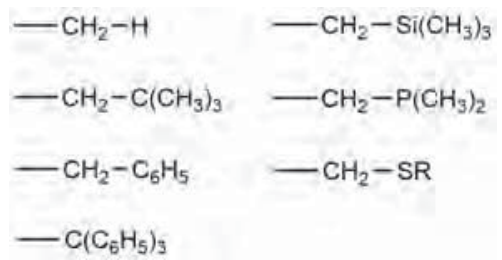

Figura 10 - Alguns ligandos $\sigma \mathrm{M}-\mathrm{C}$ sem hidrogénios $\beta$.

Partindo do principio de que se existe $\mathrm{W}(\mathrm{OR})_{6}$ e $\mathrm{W}\left(\mathrm{NR}_{2}\right)_{6}$ então $\mathrm{W}\left(\mathrm{CH}_{3}\right)_{6}$ também tem de existir, Wilkinson acabou mesmo por conseguir prepará-lo a partir de $\mathrm{LiCH}_{3}$ e $\mathrm{WCl}_{6}$, verificando que não é muito instável e é fácil de caracterizar espetroscopicamente! Confirmando a necessidade de obter saturação coordenativa, os aductos $\mathrm{W}\left(\mathrm{CH}_{3}\right)_{6}\left(\mathrm{PR}_{3}\right)$ são fáceis de isolar e ainda mais estáveis.

A partir daqui foi construindo uma biblioteca de moléculas absolutamente impensáveis para espíritos menos afoitos e, seguramente menos resilientes. Nas sua próprias palavras, “... a síntese destes compostos é mais uma arte do que uma ciência” [16]. Na Figura 11 mostram-se alguns desses compostos de todo invulgares e muitas vezes traiçoeiramente instáveis e perigosos $\left[\mathrm{Re}\left(\mathrm{CH}_{3}\right)_{6}\right.$ explodiu ferindo um dos seus colaboradores] aos quais ele carinhosamente chamava "textbook cases". 


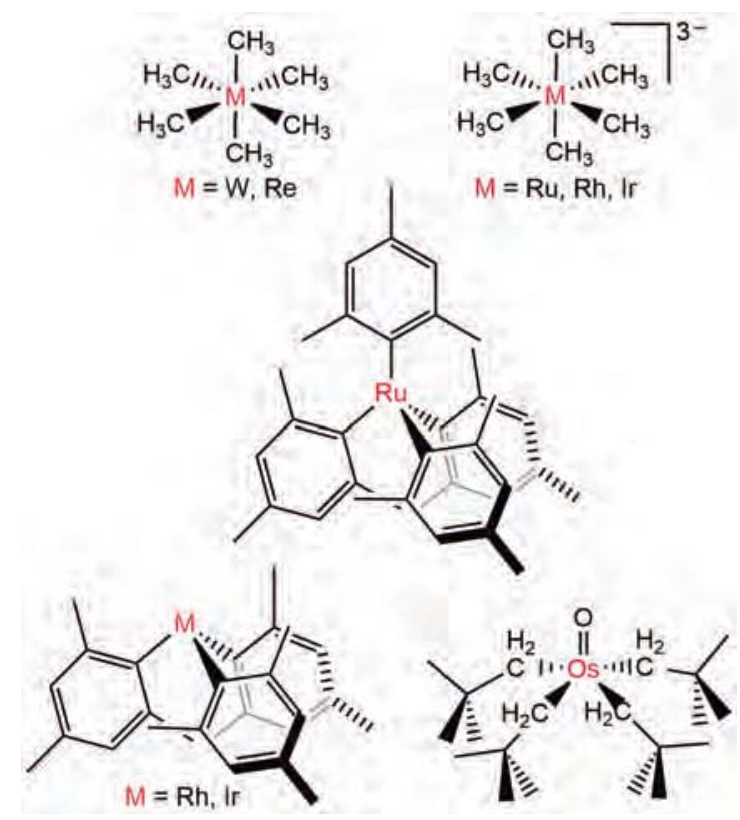

Figura 11 - Complexos organometálicos em altos estados de oxidação com ligações $\sigma$ M-C estáveis.

Nesta esteira criou uma nova química organometálica de altos estados de oxidação, já não governada pelo CO e outros ácidos $\pi$, da qual um dos primeiros exemplos foi o oxo-complexo $\operatorname{Re}(\mathrm{O})\left(\mathrm{CH}_{3}\right)_{4}$. Para abreviar uma longa história, esta nova química conduziu à descoberta da eliminação $\alpha$ e dos carbenos de Schrock (Figura 12), que estiveram na base de mais uma extraordinária saga da Química Organometálica: a metátese de alcenos e alcinos também ela premiada com o Prémio Nobel atribuído em 2005 a R. Schrock, R. Grubbs e Y. Chauvin. De alguma forma Wilkinson já o tinha anunciado na última frase da sua lição Nobel: “...e o uso de alumina tratada com hexametiltungsténio para a metátese de alcenos [18] dá boas razões para otimismo.” De facto, Wilkinson já conhecia este resultado que só foi publicado no mês seguinte ao seu discurso.

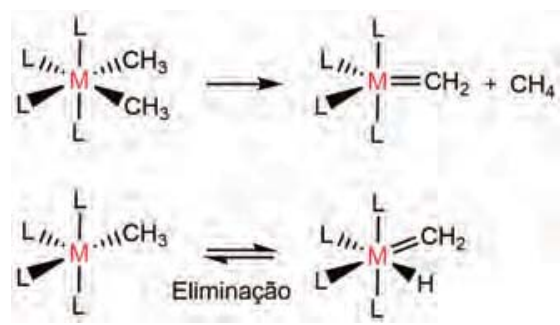

Figura 12 - Processos de ativação $\mathrm{C}_{\alpha}$ conducentes à formação de carbenos de Schrock.

Não parou de trabalhar, de manhã cedo até à tardinha, 6 a 7 dias por semana até à véspera da sua morte. A sua exigência era proverbial mas estimulante. Simplesmente esperava de cada colaborador que trabalhasse o mesmo que ele...

De facto, ao passar pela bancada de cada um dos seus estudantes todos os fins de tarde, a sua pergunta "Well, what's new?” era inteiramente genuína pois a sua característica distintiva (etos) era mesmo encontrar novos aspetos da química. Virou (quase) todas as pedras que encontrou, desde transmutar platina em ouro até à química do hidrogénio, deixando um trilho de novidades e química "fora da caixa”. De facto, a química dos derivados (methyl, ethyl, propyl... futile) era do que ele mais criticava. Certamente que nunca teria paciência para química medicinal mas a vida é assim mesmo e a diversidade uma das suas maiores riquezas. Se a minúcia e precisão de alguns nos dão moléculas capazes de apenas atingir um alvo específico na complexidade do nosso organismo, curando-o, outros, como Wilkinson, desvendam o desconhecido construindo um saber enciclopédico do qual sairão as ferramentas que permitirão ao primeiro atingir os tais alvos. Esse saber enciclopédico foi outra das preocupações de Wilkinson condensada no celebrado "Advanced Inorganic Chemistry”, um “calhamaço” insubstituível que escreveu com um dos seus primeiros doutorandos, o também celebrado Francis Albert Cotton. Por um triz salvou a primeira edição duma das tais explosões que deixou o quarteirão sem vidros. Por outro triz conseguiu terminar a $6^{\text {a }}$ edição, uma semana antes de morrer.

Numa nota pessoal cabe-me dizer que, como bisneto científico de G. Wilkinson, a minha carreira científica foi largamente construída sobre metalocenos, de onde migrei para a química organometálica dos altos estados de oxidação. Seguramente, foi esse pequeno universo de interesses que trouxe G. Wilkinson a Oxford onde, de visita a todas as bancadas dos estudantes de Malcolm Green, tive o prazer de o conhecer e trocar algumas palavras sobre o projeto que eu aí havia iniciado há cerca de um mês. No dia seguinte, já em Londres, Wilkinson foi surpreendido com a atribuição do Prémio Nobel. Escusado será dizer que nem eu tive qualquer interferência nessa nomeação, nem ele, com as suas palavras de encorajamento, evitou que esse meu projeto tivesse de ser abandonado alguns meses depois, por total inviabilidade!

\section{Referências}

[1] J.F. Young, J.A. Osborn, F.H. Jardine, G. Wilkinson, Chem. Commun. (1965) 131-132.

[2] G.B. Kauffman, J. Chem. Ed. 60 (1983) 185-186.

[3] G. Wilkinson, M. Rosenblum, M.C. Whiting, R.B. Woodward, J. Am. Chem. Soc. 74 (1952) 2125-2126.

[4] H. Werner, Angew. Chem. Int. Ed. 51 (2012) 6052-6058.

[5] M. Green, W. Griffith, http://www.independent.co.uk/incoming/obituary-professor-sir-geoffrey-wilkinson-5598553.html

[6] T.S. Piper, G. Wilkinson, J. Inorg. Nucl. Chem. 3 (1956) 104-124.

[7] J.A. Osborn, F.H. Jardine, J.F. Young, G. Wilkinson, J. Chem. Soc. A (1966) 1711-1722.

[8] C.C. Romão, Química, n. ${ }^{\circ} 143$ (2016) 27-33.

[9] J. Tsuji, K. Ohno, Tetrahedron Lett. (1965) 3969-3971.

[10] L. Vaska, J.W. DiLuzio, J. Am. Chem. Soc. 83 (1961) 27842785.

[11] C.C. Romão, Química 41 (2017) 99-106.

[12] J. Halpern, Inorg. Chim. Acta 50 (1981) 11-19.

[13] F. Joó, P. Csiba, A. Bényei, J. Chem. Soc., Chem. Commun. (1993) 1602-1604.

[14] H.B. Kagan, T.-P. Dang, J. Am. Chem. Soc. 94 (1972) 64296433.

[15] W.S. Knowles, M.J. Sabacky, B.D.Vineyard, J. Am. Chem. Soc. 97 (1975) 2567-2568.

[16] Wilkinson, G. Nobel Prize Lecture, https://www.nobelprize.org/ nobel_prizes/chemistry/laureates/1973/wilkinson-lecture.pdf.

[17] G.W. Parshall, J.J. Mrowca, Adv. Organomet. Chem. 7 (1969) 157-209.

[18] W. Mowat, J. Smith, D.A. Whan, J. Chem. Soc., Chem. Commun. (1974) 34-35. 